\title{
Studies for Validation Analysis towards Pharmacokinetic and Bio- Equivalency of Drugs in Biological Fluids
}

\section{Hideharu Shintani*}

School of Science, Chuo University, Kasuga, Bunkyo, Tokyo, Japan

Pharmacokinetic and bio-equivalency studies require very precise and accurate analytical methods that are well validated to quantify drugs in biological fluids. The analytical methods have to be sensitive enough to determine the biological sample concentration of the drug and/or its metabolite(s) after dosage of the drug [1]. In addition, the analytical methods have to be very selective to ensure reliable data, free from interference of endogenous compounds (admixtures) and possible metabolites in the biological samples. Furthermore, methods have to be as robust and cost effective, making of particular importance to bioequivalent studies. Above all, the analytical methods must be able to withstand the scrutiny of national drug registration authorities.

Bioanalytical chemistry is the qualitative and quantitative analysis of drugs in biological fluids (mainly plasma and urine) or tissue. It plays a significant role in the evaluation and interpretation of bioavailability, bioequivalence and pharmacokinetic data. The main analytical phases that comprise bioanalytical services consist of analytical method development, method validation, sample pretreatment and drug/ metabolite analysis in sample free from admixtures [2].

Owing to increased interdependence among countries in recent times it has become necessary for results of many analytical methods to be accepted internationally. Consequently, to assure a common level of quality, the need for and use of validated methods has increased (ICH Topic Q2 R1, Validation of Analytical Procedures).

Analytical methods are used for product research, product development, process control and chemical quality control. Each of the techniques used, chromatographic or spectroscopic, have their own special features and deficiencies. Whatever way the analysis is done it must be checked to see whether it does what it was intended to do; i.e. it must be validated. Each step in the analytical method must be investigated to determine the extent to which environment, matrix, or procedural variables can affect the estimation of analyte in the body fluids and tissue [3].

A full validation requires a high workload and should therefore only start when promising results are obtained from explorative validation performed during the method development. The process of validating a method cannot be separated from the actual development of method conditions, because the developer will not know whether the method conditions are acceptable until validation studies are performed. Method development clears the way for the further processes on the validation stage [4]. It must be recognized that proper validation studies require a lot of work.

A bioanalytical method is a set of all of the procedures involved in the collection, processing, storing, and analysis of a biological matrix for an analyte. Analytical methods employed for quantitative determination of drugs and their metabolites in biological fluids are the key determinants in generating reproducible and reliable data that in turn are used in the evaluation and interpretation of bioavailability, bio-equivalency and pharmacokinetics.

Method development involves evaluation and optimization of the various stages of sample preparation, chromatographic separation, detection and quantification. Method performance is determined primarily by the quality of the procedure. The main factors that are most important in determining the quality of the method are selective recovery and standardization. Analytical recovery of a method refers to whether the analytical method in question provides response for the entire amount of analyte that is contained in a sample. Recovery is usually defined as the percentage of the reference material that is measured, to that which is added to a blank. This should not be confused with the test of matrix effect in which recovery is defined as the response measured from the matrix (e.g. body fluids, tissue) as a percentage of that measured from the pure solvent (e.g. water). Results of the experiment that compare matrix to pure solvent is referred to as relative recovery and true test of recovery is referred to as absolute recovery [5].

Another important issue in method development stage is the choice of internal versus external standardization. Internal standardization is common in bioanalytical methods especially with chromatographic procedures. For internal standardization, a structural or isotopic analogue of the analyte is added to the sample prior to sample pretreatment and the ratio of the response of the analyte to that of the internal standard is plotted against the concentration.

Another important point is that the tests performed at the stage of method development should be done with the same equipment that will actually be used for subsequent routine analysis.

Validation of a method is the process by which a method is tested by the developer or user for reliability, accuracy and preciseness of its intended purpose. Data thus generated become part of the methods validation package.

Methods validation should not be a one-time situation, but the methods should be validated and also designed by the developer or user to ensure ruggedness or robustness. Methods should be reproducible

*Corresponding author: Hideharu Shintani, School of Science, Chuo University, 1-13-27, Kasuga, Bunkyo, Tokyo 112-0003, Japan, E-mail: shintani@mail. hinocatv.ne.jp

Received May 15, 2012; Accepted May 16, 2012; Published May 18, 2012

Citation: Shintani H (2012) Studies for Validation Analysis towards Pharmacokinetic and Bio-Equivalency of Drugs in Biological Fluids. Pharmaceut Anal Acta S11:e001. doi:10.4172/2153-2435.S11-e001

Copyright: (c) 2012 Shintani H. This is an open-access article distributed under the terms of the Creative Commons Attribution License, which permits unrestricted use, distribution, and reproduction in any medium, provided the original author and source are credited. 
Citation: Shintani H (2012) Studies for Validation Analysis towards Pharmacokinetic and Bio-Equivalency of Drugs in Biological Fluids. Pharmaceut Anal Acta S11:e001. doi:10.4172/2153-2435.S11-e001

Page 2 of 2

when used by other analysts, on other equivalent equipment, on other days or locations (intra and inter laboratory tests), and throughout the life of the drug product. Data that are generated for acceptance, release, stability, or pharmacokinetics will only be trustworthy if the methods used to generate the data are reliable. The process of validation and method design also should be early in the development cycle before important data are generated. Validation should be on-going in the form of re-validation with method changes.

\section{References}

1. Bressolle F, Bologna C, Kinowski JM, Arcos B, Sany J, et al. (1997) Total and free methotrexate pharmacokinetics in elderly patients with rheumatoid arthritis. A comparison with young patients. J Rheumatol 24: 1903-1909.
2. Bressolle F, Bromet-Petit M, Audran M (1996) Validation of liquid chromatographic and gas chromatographic methods. Applications to pharmacokinetics. J Chromatogr B Biomed Appl 686: 3-10.

3. Souillard A, Audran M, Bressolle F, Gareau R, Duvallet A, et al. (1996) Pharmacokinetics and pharmacodynamics of recombinant human erythropoietin in athletes. Blood sampling and doping control. Br J Clin Pharmacol 42: 355364.

4. Hartmann C, Smeyers-Verbeke J, Massart DL, McDowall RD (1998) Validation of bioanalytical chromatographic methods. J Pharm Biomed Anal 17: 193-218.

5. Causon R (1997) Validation of chromatographic methods in biomedical analysis. Viewpoint and discussion J Chromatogr B Biomed Sci Appl 689: 175180.
This article was originally published in a special issue, Pharamacokinetics: Validation, Metabolism, etc. handled by Editor(s). Dr. Hideharu Shintani, Chuo University, Japan 